\title{
American Society of Anesthesiologists Score is Not Predictive of Complication Incidence After Minimally Invasive Posterior Lumbar Spine Procedures
}

\author{
ANKUR S. NARAIN, BA, ${ }^{1}$ FADY Y. HIJJI, MD, ${ }^{1}$ BRITTANY E. HAWS, BS, ${ }^{1}$ BENJAMIN KHECHEN, BA, ${ }^{1}$ \\ KRISHNA T. KUDARAVALLI, BS, ${ }^{1}$ KELLY H. YOM, BA, ${ }^{1}$ KERN SINGH, MD ${ }^{1}$ \\ ${ }^{I}$ Department of Orthopaedic Surgery, Rush University Medical Center, Chicago, Illinois
}

\begin{abstract}
Background: Complications occurring after spinal procedures are associated with recurrent symptomatology, new-onset symptomatology, and increased health care costs. The American Society of Anesthesiologists (ASA) score is a commonly cited risk factor for complication incidence. Few investigations have been performed analyzing the relationship between ASA score and complication rate following spinal minimally invasive surgery (MIS) decompressions or fusions. Therefore, the purpose of this study is to determine whether an association exists between preoperative ASA score and the incidence of postoperative complications among patients undergoing MIS posterior lumbar decompression or fusion.

Methods: A surgical registry of patients undergoing single-level MIS posterior lumbar decompressions or fusions between 2007 and 2016 was retrospectively reviewed. Patients were stratified by preoperative ASA score $(\leq 2,>2)$. The ASA score was tested for an association with preoperative demographic, comorbidity, and perioperative characteristics using the Student $t$ test or $\chi^{2}$ analysis. Multivariate Poisson regression with robust error variance was used to test for an association between ASA score and the incidence of complications up to 6 months postoperatively.

Results: A total of 772 patients were analyzed. Of those, $86.7 \%$ had an ASA score $\leq 2$, whereas $13.3 \%$ had an ASA score $>2$. An ASA score $>2$ was associated with older age $(P<.001)$, higher comorbidity burden $(P<.001)$, and higher rates of obesity $(P<.001)$. An ASA score $>2$ was also associated with significantly longer operative time $(P=.001)$ and longer length of hospital stay $(P<.001)$. Upon multivariate analysis, ASA score category was not associated with the incidence of any complication $(P=.248)$, medical complications $(P=.227)$, or surgical complications $(P=.816)$.

Conclusions: The ASA score was not a predictive factor for complication incidence up to 6 months postoperatively. Thus, a higher ASA score should not preclude patients from being surgical candidates for MIS posterior lumbar decompressions or fusions. Further investigation is required to identify other predictive factors for complication incidence after minimally invasive spine surgery.
\end{abstract}

Level of Evidence: 3

Minimally Invasive Surgery

Keywords: minimally invasive spine surgery, transforaminal lumbar interbody fusion, lumbar decompression, medical complications, surgical complications, American Society of Anesthesiologists score, risk factors

\section{INTRODUCTION}

With the current aging of the United States' population, the prevalence of lumbar degenerative diseases will continue to increase. ${ }^{1}$ Whereas surgical management has traditionally been accomplished via open approaches, minimally invasive surgery of (MIS) the spine techniques have been gaining popularity. Compared with open approaches, MIS approaches have distinct advantages in the perioperative period including reduced intraoperative blood loss, decreased postoperative pain, and shorter length of inpatient stay. ${ }^{2-4}$ As with all surgical procedures, complications associated with MIS lumbar spine techniques are worrisome and may lead to persistent symptomatology, reduced patient satisfaction rates, and increased costs of health care. $^{5}$

The identification of risk factors for intraoperative and postoperative complications is an important topic of investigation within the orthopedic literature. One proposed risk factor is the American Society of Anesthesiologists (ASA) score, which represents a subjective measure of a patient's overall 
physical health. ${ }^{6}$ The ASA score is expressed on a 5point scale, with ASA class I representing a "healthy" patient and ASA class V representing a "moribund" patient. Many previous studies within the orthopedic literature have associated higher ASA scores with an increased likelihood of postoperative medical and surgical complications. ${ }^{7-15}$

To our knowledge, there have been no previous investigations examining the relationship between ASA score and complications after MIS spinal decompression or fusion. As such, the purpose of this study was to determine whether an association exists between ASA score and both medical and surgical complications after MIS posterior lumbar decompression and fusion procedures.

\section{MATERIALS AND METHODS}

\section{Patient Selection}

Institutional review board approval (ORA No. 14051301) was obtained for this study. A prospectively maintained surgical database of patients who underwent primary, single-level MIS posterior lumbar decompression or fusion between 2007 and 2016 for degenerative pathologies was retrospectively reviewed. Fusion procedures consisted of MIS transforaminal lumbar interbody fusion. Decompression procedures included MIS lumbar laminectomy, laminotomy, or discectomy. All procedures were performed by the senior author (K.S.) at a single academic site. These procedures were chosen because they were performed using a posterior minimally invasive approach through a tubular retractor system. Patients were excluded from this study if they had undergone a procedure for nondegenerative pathology such as trauma or if a minimum of 6-month follow-up was not obtained.

\section{Data Collection}

Patients were stratified by ASA score into low ASA score $(\leq 2)$ and high ASA score $(>2)$ groups. An ASA score of 2 was chosen as the cutoff between groups to differentiate between patients with minimal or mild systemic disease and those with severe disease manifestations. In addition, such grouping of ASA score cohorts is consistent with other studies in the spine literature analyzing ASA score as a risk factor. ${ }^{16,17}$ Demographic information including age, sex, smoking status, Charlson Comorbidity Index (CCI), and body mass index (BMI) were compared between ASA score groups. A modified form of the
CCI with the age component removed was used so that age and CCI could both be used as independent variables in subsequent statistical analyses. Perioperative variables including operative time, estimated intraoperative blood loss, length of stay, and type of procedure were also compared between ASA score groups.

Patient medical records were reviewed to determine the incidence of perioperative and postoperative complications up to 6 months after each procedure. Medical complications measured included aspiration/reintubation, urinary retention requiring recatheterization, urinary tract infection, acute renal failure, postoperative anemia requiring transfusion, altered mental status, deep venous thrombosis, pulmonary embolism, pneumothorax, cardiac arrhythmia, ileus, and pneumonia. Surgical complications included intraoperative durotomy, epidural hematoma, instrumentation failure requiring reoperation, surgical site infection requiring subsequent incision and drainage, new onset neurologic dysfunction, and musculoskeletal/bone pathologies. The incidence of any complication, medical complications, and surgical complications were compared between ASA score groups.

\section{Statistical Analysis}

Statistical analysis was performed using Stata/ MP 13.1 for Mac (StataCorp LP, College Station, TX). The ASA score was tested for an association with demographic and perioperative variables using the Student $t$ test or $\chi^{2}$ analysis for continuous and categorical variables, respectively. Multivariate Poisson regression with robust error variance was used to determine whether an association existed between ASA score and the incidence of any complication, medical complications, or surgical complications up to 6 months postoperatively. The regression model was controlled for age, gender, BMI, and procedure type. Statistical significance was set at $P<.05$.

\section{RESULTS}

A total of 772 patients were included in this analysis. Of these, 86.7\% (669) had an ASA score $\leq 2$, whereas $13.3 \%$ (103) had an ASA score $>2$. No patients in this population had an ASA score of 5 . Baseline demographic characteristics were compared between ASA score groups (Table 1). Higher ASA score was associated with older age (57.1 vs 
Table 1. Baseline characteristics by ASA score.

\begin{tabular}{|c|c|c|c|}
\hline & $\begin{array}{l}\mathrm{ASA} \leq \mathbf{2} \\
(\mathrm{n}=669)\end{array}$ & $\begin{array}{l}\text { ASA > 2 } \\
(n=103)\end{array}$ & $P$ Value ${ }^{\mathrm{a}, \mathrm{b}}$ \\
\hline Age, mean $\pm \mathrm{SD}$ & $45.8 \pm 12.8$ & $57.1 \pm 12.5$ & $<.001$ \\
\hline Sex, \% (n) & & & .687 \\
\hline Female & $36.0(241)$ & $34.0(35)$ & \\
\hline Male & $64.0(428)$ & $66.0(68)$ & \\
\hline Smoking status, \% (n) & & & .540 \\
\hline Nonsmoker & $79.3(530)$ & $76.7(79)$ & \\
\hline Smoker & $20.7(138)$ & $23.3(24)$ & \\
\hline $\mathrm{CCI}$, mean $\pm \mathrm{SD}$ & $0.8 \pm 1.2$ & $2.0 \pm 1.5$ & $<.001$ \\
\hline BMI category, \% (n) & & & $<.001$ \\
\hline Obese & $40.9(395)$ & $64.7(66)$ & \\
\hline Nonobese & $59.1(273)$ & $35.3(36)$ & \\
\hline
\end{tabular}

Abbreviations: ASA, American Society of Anesthesiologists; BMI, body mass index; CCI, Charlson Comorbidity Index.

${ }^{\text {a }} P$ value was calculated for each category using $\chi^{2}$ analysis (categorical) or Student $t$ test (continuous).

${ }^{\mathrm{b} B o l d f a c e}$ indicates statistical significance.

45.8 years, $P<.001$ ), higher comorbidity burden as expressed by the modified CCI (2.0 vs 0.8 , $P<.001)$, and a higher prevalence of obesity $(64.7 \%$ vs $40.9 \%, P<.001)$. There were no significant differences in the distribution of sex or smoking status between groups ( $P>.05$ for each).

Perioperative characteristics were summarized and compared between ASA score groups (Table 2). Patients with higher ASA scores were more likely to undergo a fusion procedure $(68.0 \%$ vs $53.7 \%$, $P=.007)$ than were those with lower ASA scores. Higher ASA score was also associated with longer operative times ( 94.5 vs 77.9 minutes, $P=.001$ ) and prolonged length of inpatient stay (47.8 vs 34.3 hours, $P<.001)$. There were no statistically significant differences in estimated intraoperative blood loss between groups $(P=07)$.

Complication rates were determined for individual medical and surgical complications (Table 3). The risk for the incidence of any complication, medical complications, and surgical complications were compared between ASA score groups (Table

Table 2. Baseline operative characteristics by ASA score.

\begin{tabular}{|c|c|c|c|}
\hline & $\begin{array}{l}\mathrm{ASA} \leq 2 \\
(\mathrm{n}=669)\end{array}$ & $\begin{array}{l}\text { ASA }>2 \\
(n=103)\end{array}$ & $P$ Value $^{\mathrm{a}, \mathrm{b}}$ \\
\hline $\begin{array}{l}\text { Operative time, } \\
\text { mean } \pm \mathrm{SD}, \min \end{array}$ & $77.9 \pm 45.9$ & $94.5 \pm 53.1$ & .001 \\
\hline $\begin{array}{l}\text { Estimated blood loss, } \\
\text { mean } \pm \mathrm{SD}, \mathrm{mL}\end{array}$ & $56.7 \pm 58.3$ & $68.1 \pm 64.3$ & .070 \\
\hline $\begin{array}{l}\text { Length of stay, } \\
\text { mean } \pm \mathrm{SD}, \mathrm{h}\end{array}$ & $34.3 \pm 36.4$ & $47.8 \pm 35.8$ & $<.001$ \\
\hline Procedure, \% (n) & & & .007 \\
\hline Fusion & 53.7 (359) & $68.0(70)$ & \\
\hline Decompression & $46.3(310)$ & $32.0(33)$ & \\
\hline
\end{tabular}

Abbreviation: ASA, American Society of Anesthesiologists.

${ }^{a} P$ value was calculated for each category using $\chi^{2}$ analysis (categorical) or

Student $t$ test (continuous).

${ }^{\mathrm{b}}$ Boldface indicate statistical significance.
Table 3. Incidence of medical and surgical complications.

\begin{tabular}{|c|c|c|}
\hline & $\begin{array}{l}\mathrm{ASA} \leq 2 \\
(\mathrm{n}=669)\end{array}$ & $\begin{array}{l}\mathrm{ASA}>2 \\
(\mathrm{n}=103)\end{array}$ \\
\hline \multicolumn{3}{|l|}{ Medical complications, n (\%) } \\
\hline Aspiration/reintubation & $1(0.2)$ & $0(0.0)$ \\
\hline Urinary retention $^{\mathrm{a}}$ & $38(5.7)$ & $12(11.7)$ \\
\hline UTI & $2(0.3)$ & $0(0.0)$ \\
\hline Acute renal failure & $2(0.3)$ & $0(0.0)$ \\
\hline Postoperative transfusion & $4(0.6)$ & $1(1.0)$ \\
\hline Altered mental status & $4(0.6)$ & $2(2.0)$ \\
\hline DVT & $1(0.2)$ & $0(0.0)$ \\
\hline $\mathrm{PE}$ & $0(0.0)$ & $0(0.0)$ \\
\hline Pneumothorax & $0(0.0)$ & $0(0.0)$ \\
\hline Arrhythmia & $1(0.2)$ & $0(0.0)$ \\
\hline Ileus & $4(0.6)$ & $0(0.0)$ \\
\hline Pneumonia & $0(0.0)$ & $0(0.0)$ \\
\hline \multicolumn{3}{|l|}{ Surgical complications, n (\%) } \\
\hline Durotomy & $4(0.6)$ & $0(0.0)$ \\
\hline Epidural hematoma & $2(0.3)$ & $0(0.0)$ \\
\hline Instrumentation failure ${ }^{b}$ & $3(0.5)$ & $0(0.0)$ \\
\hline Surgical site infection $^{c}$ & $1(0.2)$ & $2(2.0)$ \\
\hline Neurologic dysfunction & $0(0.0)$ & $0(0.0)$ \\
\hline MSK/Bone ${ }^{\mathrm{d}}$ & $1(0.2)$ & $0(0.0)$ \\
\hline
\end{tabular}

Abbreviations: ASA, American Society of Anesthesiologists; DVT, deep venous thrombosis; MSK, musculoskeletal; PE, pulmonary embolism; UTI, urinary tract infection.

${ }^{a}$ Urinary retention requiring recatheterization.

${ }^{\mathrm{b}}$ All cases had postoperative cage migration requiring reoperation.

${ }^{\mathrm{c}}$ Surgical site infection requiring incision and drainage.

${ }^{\mathrm{d}}$ One case of neuroforaminal bone growth with resultant symptomatology.

4). An ASA score $>2$ was not an independent risk factor for the incidence of any complication (relative risk $[\mathrm{RR}]=1.36,95 \%$ confidence interval $[\mathrm{CI}]=0.81-2.27, P=.248)$. An ASA score $>2$ was also not an independent risk factor for the incidence of medical complications $(\mathrm{RR}=1.43$, $95 \% \mathrm{CI}=0.80-2.53, P=.227)$ or surgical complications $(\mathrm{RR}=0.83,95 \% \mathrm{CI}=0.17-4.10, P=.816)$ up to 6 months postoperatively.

\section{DISCUSSION}

Intraoperative and postoperative complications after orthopedic spine procedures can have significant adverse effects on surgical efficacy and clinical

Table 4. Multivariate analysis for complication risk by ASA score.

\begin{tabular}{|c|c|c|c|c|}
\hline & $\begin{array}{l}\text { Relative } \\
\text { Risk }\end{array}$ & $\begin{array}{l}\text { Standard } \\
\text { Error }\end{array}$ & $\begin{array}{l}\text { 95\% Confidence } \\
\text { Interval }\end{array}$ & $P$ Value ${ }^{\mathrm{a}, \mathrm{b}}$ \\
\hline \multicolumn{5}{|c|}{ Any complication } \\
\hline $\mathrm{ASA} \leq 2$ & Ref & $\ldots$ & $\cdots$ & $\ldots$ \\
\hline $\mathrm{ASA}>2$ & 1.36 & 0.36 & $0.81-2.27$ & .248 \\
\hline \multicolumn{5}{|c|}{ Medical complications } \\
\hline $\mathrm{ASA} \leq 2$ & Ref & $\ldots$ & $\ldots$ & $\ldots$ \\
\hline $\mathrm{ASA}>2$ & 1.43 & 0.42 & $0.80-2.53$ & .227 \\
\hline \multicolumn{5}{|c|}{ Surgical complications } \\
\hline $\mathrm{ASA} \leq 2$ & Ref & $\ldots$ & $\ldots$ & $\ldots$ \\
\hline $\mathrm{ASA}>2$ & 0.83 & 0.68 & $0.17-4.10$ & .816 \\
\hline
\end{tabular}

Abbreviation: ASA, American Society of Anesthesiologists.

${ }^{\text {a }} P$ value was calculated using Poisson regression with robust error variance controlled for age, gender, body mass index, and procedure type.

${ }^{\mathrm{b}}$ Boldface indicates statistical significance. 
outcome. Identification of risk factors for the incidence of complications is a heavily studied topic within the general orthopedic literature. Many previous studies have identified high ASA scores as a risk factor for both medical and surgical complications after joint arthroplasty procedures. ${ }^{7,9,11-13}$ The purpose of this study was to determine whether ASA score was a predictor of complication incidence in patients undergoing minimally invasive posterior lumbar spine surgery.

The results of this study indicate that patients with ASA score $>2$ are older, more likely to be obese, and have a higher comorbidity burden than patients with ASA score $\leq 2$. In addition, patients in the higher ASA score group had significantly longer operative times and length of inpatient stay. However, despite these factors, ASA score group was not found to be associated with the incidence of any complication, medical complications, or surgical complications up to 6 months after each procedure.

The lack of an association between ASA score and complication incidence in this study differs from a significant portion of the orthopedic literature, especially regarding joint arthroplasty. ${ }^{7,9,11-13}$ Pulido et al, ${ }^{11}$ in a study of 9245 patients undergoing total hip or total knee arthroplasty, analyzed risk factors for the development of periprosthetic joint infection up to 1-year postoperatively. The authors determined that ASA score $>2$ was an independent risk factor for periprosthetic joint infections. In addition, Johnson et $\mathrm{al}^{7}$ performed a study analyzing complication rates in 452 patients undergoing total shoulder arthroplasty (TSA), reverse TSA, or revision TSA. An ASA score $>2$ was once again found to be a significant independent predictor of both surgical complications and prosthesis failure up to 6 months postoperatively.

Within the spine literature, there is some variation regarding the relationship between ASA score and complication rate. ${ }^{8,10,17-20}$ Schoenfeld et $\mathrm{al}^{8}$ performed a study of 3475 patients undergoing spine surgery using the American College of Surgeons National Surgical Quality Improvement Program (ACS-NSQIP) database. Up to 30 days postoperatively, ASA score $>2$ was identified as an independent predictor of the incidence of $\geq 1$ complication, $\geq 1$ major complication, and 30-day mortality rate. Similarly, $\mathrm{Fu}$ et $\mathrm{al}^{20}$ used the Scoliosis Research Society Morbidity and Mortality database to analyze 22857 patients undergoing spinal procedures. In their analysis, higher ASA scores were associated with both an increased rate of complications and postoperative mortality. Of note, both studies performed by Schoenfeld et al and $\mathrm{Fu}$ et al used cohorts consisting of patients undergoing a mixture of cervical and lumbar procedures for both degenerative and nondegenerative pathologies. More recent investigations focusing on singleprocedure cohorts have produced results similar to our study. Specifically, Lim et $\mathrm{al}^{17}$ used the ACSNSQIP database to investigate 6148 patients undergoing single-level anterior cervical discectomy and fusion procedures. After the creation of 1628 propensity-matched pairs, multivariate regression analysis determined that there was no association between ASA score $>2$ and the incidence of adverse events up to 30 days postoperatively.

The contrast in findings between the present study and others in the orthopedic literature may be associated with several factors. One explanation may be correlated with the inherent differences in procedural characteristics between MIS and other surgical approaches. Specifically, MIS approaches use smaller incisions, require smaller surgical exposure areas via tubular retraction, and allow for faster postoperative ambulation and recovery. ${ }^{21-25}$ The overall decreased invasiveness and reduced postoperative functional impairment of these approaches may mitigate the risk for medical and surgical complications in patients with higher ASA scores and more overall comorbidities. This is in contrast to joint arthroplasty and open spine procedures, in which increased procedural invasiveness, blood loss, and postoperative functional impairment may lead to increased complication rates in patients who are in poor physical health.

Another factor in the contrasting findings between the present study and other studies in the literature may involve differences in study design. Within the spine literature, the majority of prior investigations involving preoperative ASA score classification were conducted using cohorts consisting of patients undergoing a wide spectrum of spinal procedures. ${ }^{8,10,18,20}$ As such, the findings of these studies may not be directly comparable to studies investigating more specific surgical cohorts. In addition, the lack of an association between ASA score and complications in this study as compared with previous investigations suggests that the predictive value of ASA score for postoperative 
morbidity may be approach or procedure specific. The previously mentioned study by Lim et $\mathrm{al}^{17}$ expressed a similar sentiment, while also suggesting that more procedure-specific investigations of the utility of the ASA score are required.

The results of this study bring into question the utility of the ASA score in predicting operative morbidity after MIS posterior lumbar decompression or fusion. The applicability of the ASA score is limited by its subjective assessment, which can lead to variable assignment of ASA values by different practitioners. ${ }^{26,27}$ Mak et al, ${ }^{27}$ using a survey of anesthesiologists, determined that the interobserver agreement for ASA score assignment ranged from $31 \%$ to $85 \%$. In addition, the calculated $\kappa$ values for interobserver reliability designated only "fair" agreement between practitioners. In a similar investigation, Owens et $\mathrm{al}^{26}$ determined that anesthesiologists agreed on ASA score assignment in an average of only 5.9 out of 10 cases. This variability in ASA score assignment indicates a need for the development of alternative risk-stratification tools for operative morbidity after MIS posterior lumbar decompression or fusion.

This study is not without limitations. First, this study was performed retrospectively and thus may be subject to selection bias and unknown confounders. Second, this study was performed using patients treated by a single surgeon at a single academic site. As such, the generalizability of the results may be limited. Third, the ASA score was not designed with the intention to predict the incidence of operative complications. However, recent studies have associated ASA score with surgical complication incidence, justifying its inclusion as a potential risk factor for surgical complications. ${ }^{7,28}$ Fourth, the sample size of 772 patients is relatively small, especially given that only 103 had an ASA score $>2$. As such, this study may be underpowered to detect a statistically significant difference in complication rate between ASA score groups. In addition, this small sample size was coupled with low incidences of some specific complications, thus limiting our ability to directly compare rates of those specific complications. However, this study represents the largest known investigation of ASA score and complication incidence in an MIS-specific patient sample. Finally, a small subset of patients were removed from the analysis because they did not achieve 6-month follow-up. This may result in a slight underestimate in the true complication rate after MIS posterior lumbar decompression or fusion, because some of these patients may have received care for postoperative complications from other health care providers. However, it is our belief that our practice represents a relatively closed population with high rates of overall patient retention.

\section{CONCLUSIONS}

Higher preoperative ASA score classification was predictive of increased operative times and longer length of inpatient stay after MIS posterior lumbar decompression or fusion. However, ASA score was not an independent predictor of the incidence of either medical or surgical complications up to 6 months after these procedures. As such, higher ASA scores should not preclude patients from being surgical candidates for MIS posterior lumbar decompression or fusion. In addition, the lack of an association between ASA score and complication incidence indicates a need for the development of an alternative risk-stratification tool for postoperative morbidity after MIS posterior lumbar decompression or fusion.

\section{REFERENCES}

1. Fehlings MG, Tetreault L, Nater A, et al. The aging of the global population: the changing epidemiology of disease and spinal disorders. Neurosurgery. 2015;77(Suppl 4):S1-S5.

2. Patel AA, Zfass-Mendez M, Lebwohl NH, et al. Minimally invasive versus open lumbar fusion: a comparison of blood loss, surgical complications, and hospital course. Iowa Orthop J. 2015;35:130-134.

3. Singh K, Nandyala SV, Marquez-Lara A, et al. A perioperative cost analysis comparing single-level minimally invasive and open transforaminal lumbar interbody fusion. Spine J. 2014;14(8):1694-1701.

4. Seng C, Siddiqui MA, Wong KP, et al. Five-year outcomes of minimally invasive versus open transforaminal lumbar interbody fusion: a matched-pair comparison study. Spine (Phila Pa 1976) 2013;38(23):2049-2055.

5. Goldstein CL, Macwan K, Sundararajan K, et al. Perioperative outcomes and adverse events of minimally invasive versus open posterior lumbar fusion: meta-analysis and systematic review. J Neurosurg Spine. 2016;24(3):416-427.

6. American Society of Anesthesiologists. New classification of physical status. Anesthesiology 1963;24:111.

7. Johnson CC, Sodha S, Garzon-Muvdi J, et al. Does preoperative American Society of Anesthesiologists score relate to complications after total shoulder arthroplasty? Clin Orthop Relat Res. 2014;472(5):1589-1596.

8. Schoenfeld AJ, Ochoa LM, Bader JO, et al. Risk factors for immediate postoperative complications and mortality following spine surgery: a study of 3475 patients from the 
National Surgical Quality Improvement Program. J Bone Joint Surg Am. 2011;93(17):1577-1582.

9. Bozic KJ, Lau E, Kurtz S, et al. Patient-related risk factors for postoperative mortality and periprosthetic joint infection in Medicare patients undergoing TKA. Clin Orthop Relat Res. 2012;470(1):130-137.

10. Veeravagu A, Patil CG, Lad SP, et al. Risk factors for postoperative spinal wound infections after spinal decompression and fusion surgeries. Spine (Phila Pa 1976). 2009;34(17):1869-1872.

11. Pulido L, Ghanem E, Joshi A, et al. Periprosthetic joint infection: the incidence, timing, and predisposing factors. Clin Orthop Relat Res. 2008;466(7):1710-1715.

12. Woodfield JC, Beshay NM, Pettigrew RA, et al. American Society of Anesthesiologists classification of physical status as a predictor of wound infection. ANZ $J$ Surg. 2007;77(9):738-741.

13. Mortazavi SM, Kakli H, Bican O, et al. Perioperative stroke after total joint arthroplasty: prevalence, predictors, and outcome. J Bone Joint Surg Am. 2010;92(11):2095-2101.

14. Culver DH, Horan TC, Gaynes RP, et al. Surgical wound infection rates by wound class, operative procedure, and patient risk index. National Nosocomial Infections Surveillance System. Am J Med. 1991;91(3B):152S-157S.

15. Bjorgul K, Novicoff WM, Saleh KJ. American Society of Anesthesiologist physical status score may be used as a comorbidity index in hip fracture surgery. $J$ Arthroplasty. 2010;25(6 Suppl):134-137.

16. Lim S, Edelstein AI, Patel AA, et al. Risk Factors for postoperative infections following single-level lumbar fusion surgery. Spine (Phila Pa 1976). 2018;43(3):215-222.

17. Lim S, Carabini LM, Kim RB, et al. Evaluation of American Society of Anesthesiologists classification as 30-day morbidity predictor after single-level elective anterior cervical discectomy and fusion. Spine J. 2017;17(3):313-320.

18. Whitmore RG, Stephen JH, Vernick C, et al. ASA grade and Charlson Comorbidity Index of spinal surgery patients: correlation with complications and societal costs. Spine J. 2014;14(1):31-38.

19. Tang H, Zhu J, Ji F, et al. Risk factors for postoperative complication after spinal fusion and instrumentation in degenerative lumbar scoliosis patients. J Orthop Surg Res. 2014;9(1):15.

20. Fu KM, Smith JS, Polly DW Jr, et al. Correlation of higher preoperative American Society of Anesthesiology grade and increased morbidity and mortality rates in patients undergoing spine surgery. J Neurosurg Spine. 2011;14(4):470474.

21. Kulkarni AG, Patel RS, Dutta S. Does minimally invasive spine surgery minimize surgical site infections? Asian Spine J. 2016;10(6):1000-1006.
22. Regev GJ, Kim CW, Salame K, et al. A comparison of different minimally invasive and open posterior spinal procedures using volumetric measurements of the surgical exposures. Clin Spine Surg. 2017;30(9):425-428.

23. Virdee JS, Nadig A, Anagnostopoulos G, et al. Comparison of peri-operative and 12-month lifestyle outcomes in minimally invasive transforaminal lumbar interbody fusion versus conventional lumbar fusion. $B r \quad J$ Neurosurg. 2017;31(2):167-171.

24. Khan NR, Clark AJ, Lee SL, et al. Surgical outcomes for minimally invasive vs open transforaminal lumbar interbody fusion: an updated systematic review and meta-analysis. Neurosurgery 2015;77(6):847-874, discussion 874.

25. Johans SJ, Amin BY, Mummaneni PV. Minimally invasive lumbar decompression for lumbar stenosis: review of clinical outcomes and cost effectiveness. J Neurosurg Sci. 2015;59(1):37-45.

26. Owens WD, Felts JA, Spitznagel EL Jr. ASA physical status classifications: a study of consistency of ratings. Anesthesiology. 1978;49(4):239-243.

27. Mak PH, Campbell RC, Irwin MG, et al. The ASA physical status classification: inter-observer consistency. American Society of Anesthesiologists. Anaesth Intensive Care. 2002;30(5):633-640.

28. Leschinger T, Raiss P, Loew M, et al. Total shoulder arthroplasty: risk factors for intraoperative and postoperative complications in patients with primary arthritis. J Shoulder Elbow Surg. 2017;26(3):e71-e77.

Disclosures and COI: No funds were received in support of this work. No benefits in any form have been or will be received from any commercial party related directly or indirectly to the subject of this manuscript.

Corresponding Author: Kern Singh, MD, Professor, Department of Orthopaedic Surgery

Rush University Medical Center, 1611 W. Harrison St, Suite 300, Chicago, IL 60612. Phone: (312) 4322373; Fax: (708) 409-5179; Email: kern.singh@ rushortho.com.

Published 29 February 2020

This manuscript is generously published free of charge by ISASS, the International Society for the Advancement of Spine Surgery. Copyright (C) 2020 ISASS. To see more or order reprints or permissions, see http://ijssurgery.com. 